\title{
New Insight into the Role of Patients During Medical Appointments: A Synthesis of Three Qualitative Studies
}

\author{
Ludmila Marcinowicz • Teresa Pawlikowska • \\ Jerzy Konstantynowicz $\cdot$ Slawomir Chlabicz
}

Published online: 25 March 2014

(C) The Author(s) 2014. This article is published with open access at Springerlink.com

\begin{abstract}
Background The complexity of the doctor-patient relationship requires in-depth research to enable a better understanding of the nature of the doctor's appointment.

Objective To explore how patients can facilitate their medical appointments, and how they can be responsible for their relationship with their doctors.

Methods A synthesis of our previous three qualitative studies of doctor-patient relationships focussed on the consultations. The analysis involved three qualitative studies based on in-depth interviews with 94 patients of family doctors in Poland.

Results A detailed analysis of these data allowed us to distinguish several different ways in which patients participate in medical consultation, namely: 1 . facilitating the visit; 2 . having an impact on both patient and doctor perception of satisfaction with the visit; and 3. showing concern for the doctor, understanding the doctor's situation and having empathy.

Conclusion This study concerning patient-doctor interactions shows that each participant can explicitly provide emotional support for the other, despite the evident
\end{abstract}

L. Marcinowicz $(\bowtie) \cdot S$. Chlabicz

Department of Family Medicine and Community Nursing,

Medical University of Bialystok, Mieszka I 4 B, 15054

Białystok, Poland

e-mail: ludmila.marcinowicz@umb.edu.pl

T. Pawlikowska

Health Professions Education Centre, Royal College of Surgeons in Ireland RCSI, 121 St Stephen's Green, Dublin 2, Ireland

J. Konstantynowicz

Department of Pediatrics and Developmental Disorders, Medical University of Bialystok, Waszyngtona 17, 15274 Białystok, Poland asymmetry in the roles of doctor and patient. Patients can substantially contribute to the personalisation of their relationship with the doctor, which is often facilitated by the repetition and regularity of the interaction.

\section{Key Points for Decision Makers}

This paper shows that patients can themselves act to facilitate their medical appointment via their subjectivity and activity in the doctor-patient relationship.

The patient's role facilitates the medical appointments and allows better co-operation between the two parties.

Patients allow the doctor the right to be vulnerable (as a fellow human), and express an understanding of the nature of his/her work.

A holistic approach to the patients' role in their relationships with doctors, attending to the boundaries between them and reducing asymmetry in these two roles in terms of their activity appears to be essential for changing the course of the medical appointment.

\section{Introduction}

Currently, patients have been assigned a number of new roles in healthcare: decision maker, co-producer of health, evaluator and active citizen, whose voices should be taken into account by healthcare professionals [1]. The impact of 
the patient can be seen both at the level of the healthcare system and at the level of medical consultation. The relationship between doctor and patient can be analysed in different ways: the roles played by doctor and patient, their behaviours and the dynamics of the consultation [2]. The complexity of this relationship can be explained by considering two major theories: social interaction and reciprocity theory [3].

In medical communication, two types of behaviours are reported and discussed: instrumental or task behaviour (oriented technical medical care) and affective or socio-emotional behaviour (oriented interpersonal care) [4]. Social interaction theory assumes that patients typically identify doctors' socio-emotional behaviour and respond to it. Regarding the doctor-patient relationship, this theory assumes that patients seek out medical advice and consult their doctors for two reasons: treating the illness and relieving anxiety, which the doctor addresses through task behaviours (e.g. prescribing medication) and socio-emotional behaviours (e.g. expressions of concern and reassurance) [3,5]. Reciprocity theory predicts that patients recognise and respond to both socio-emotional as well as instrumental (task) behaviours, and respond to these behaviours in a similar way. This theory assumes that people feel obligated to return those goods and services they receive from others. For example, the doctor providing advice/information should be reciprocated by patient compliance $[3,6]$.

Different types of relationships between patients and their doctors have been described: positive long-term relationships (for a majority of the adult population), doctor-controlled relationships (leaving decision making or passing responsibility to the doctor), unhappy relationships (a minority of people) and ambivalent relationships [7]. Although quantitative studies are of great value in the description of the relationship between a doctor and a patient, qualitative research provides a fuller understanding of this relationship.

In Poland, relatively little qualitative research in the context of healthcare is undertaken. Focus group-based studies are performed to explore challenges faced by Polish family doctors in the management of patients with unexplained symptoms. In these studies, family doctors mainly stress their own difficulties in dealing with heartsink patients [8]. Our previous qualitative research amongst patients in Poland has provided information on how patients assess healthcare [9], how they define satisfaction with family doctor care [10], express negative opinions or explain the causes of dissatisfaction with healthcare [11] and express healthcare priorities [12].

However, the complexity of the doctor-patient relationship requires further in-depth research to enable a better understanding of the nature of the doctor's appointment. Synthesis of our own three previously published qualitative studies was undertaken to determine how patients can facilitate their medical appointments, and how they can be responsible for the relationship with their doctors.

\section{Material and Research Procedures}

The analysis involved three qualitative studies based on indepth interviews with patients of family doctors in Poland. The first study was conducted in 2002 and included 28 patients using the services of one family medicine practice. It aimed to identify the way patients evaluate healthcare, what words and expressions they use, and in what context the term 'satisfaction' with care is used [9]. The second study was carried out in 2007-2008, with the involvement of 36 patients in different regions of Poland. Its aim was to explore how satisfaction is understood from the perspective of patients receiving care from family doctors [10] and to determine how Polish patients verbally express negative opinions of their healthcare services [11]. The third study, completed in 2010, was designed to explore which aspects of care provided by family doctors are the most important for the elderly and it included 30 older patients treated by family doctors in Bialystok and Krakow [12]. The characteristics of participants in all three studies are presented in Table 1. All interviews $(n=94)$ were conducted by the same person (LM) in participants' own homes, with some exceptions. The interviews (lasting from $25 \mathrm{~min}$ to $2.5 \mathrm{~h}$ ) were based on interview guides (see Appendix). The interviews were tape recorded and transcribed verbatim. Ethics Committee approval was given by the Medical University of Bialystok for the three research projects of which the present synthesis study was comprised.

\subsection{Data Analysis}

Interview transcripts were analysed using the grounded theory, according to Strauss and Corbin [13]. First, open

Table 1 Characteristics of studied participants $(n=94)$

\begin{tabular}{llll}
\hline Characteristics & $\begin{array}{l}\text { Study I } \\
n=28\end{array}$ & $\begin{array}{l}\text { Study II } \\
n=36\end{array}$ & $\begin{array}{l}\text { Study III } \\
n=30\end{array}$ \\
\hline $\begin{array}{l}\text { Mean age; years (range) } \\
\text { Gender }\end{array}$ & $61(27-86)$ & $53(20-78)$ & $74(65-87)$ \\
$\quad$ Female & 21 & 20 & 18 \\
$\quad$ Male & 7 & 16 & 12 \\
Education & & & \\
Elementary & 5 & 5 & 7 \\
Vocational & 2 & 4 & 10 \\
Secondary & 13 & 16 & 7 \\
University & 8 & 11 & 6 \\
\hline
\end{tabular}


coding was carried out, i.e. "the analytic process through which concepts are identified and their properties and dimensions are discovered in data" [13, p. 101] and lineby-line analysis (especially important in the beginning of the study) was performed. Contents of the transcripts were thoroughly read and re-read by two authors (LM and TP), who then coded the concepts. In the next stage of the analysis, axial coding (relating categories to their sub-categories) and selective coding (integrating and further refining the theory) were used. The codes were grouped into themes to identify key features concerning the patient's role. The analysis proceeded with discussion and feedback from the sociologist involved in the analysis of all three studies.

For the final stage of this research, we synthesised the three previous studies, which revealed new perspectives and results that had not been sufficiently evident in the individual, separate research processes.

\section{Results}

A detailed analysis of these data allowed us to distinguish several different ways in which patients participate in a medical consultation, namely: facilitating the visit; having an impact on both patient and doctor perception of satisfaction with the visit; and showing concern for the doctor, understanding the doctor's situation and having empathy (Table 2).

\subsection{Ways of Facilitating the Visit}

Patients' interviews clearly show that they care about maintaining a good relationship with their doctor during their visit and try to facilitate its progress through concordance with doctor's recommendations, openness to cooperation, respecting the doctor's time and creating a pleasant atmosphere during the appointment.

Table 2 Different ways patients participate in the medical consultation

\begin{tabular}{ll}
\hline $\begin{array}{l}\text { Ways patients participate } \\
\text { Facilitating the visit }\end{array}$ & $\begin{array}{l}\text { Contribution to the visit } \\
\text { Concordance } \\
\text { Respecting the doctor's time } \\
\text { Creating a relaxed atmosphere } \\
\text { during the visit }\end{array}$ \\
$\begin{array}{l}\text { Positive } \\
\text { Negative }\end{array}$ \\
$\begin{array}{l}\text { Having concern for the doctor and } \\
\text { understanding } \\
\text { the doctor's situation }\end{array}$ & $\begin{array}{l}\text { Perceiving the doctor as human } \\
\text { Empathy }\end{array}$ \\
\hline
\end{tabular}

\subsubsection{Concordance}

Patients, by their positive attitude to life and discipline in matters relating to health, can contribute to the smooth running of the visit, and also to health improvement measures.

"I'm not a picky patient. (...) I'm not looking for problems. I respond to specific questions. I take medications regularly, I adhere to recommendations." (Study I, male patient, aged 50 years, secondary education).

"I adhered to his treatment and after two weeks I was healthy." (Study II, female patient, aged 44 years, higher education).

"I just listen to what he is saying to me." (Study III, male patient, aged 72 years, vocational education).

Others Emphasised a Willingness to Cooperate

"I'm trying to cooperate with the doctor." (Study III, male patient, aged 75 years, higher education).

Patients also mentioned the necessity to tell the truth to the doctor.

"You have to tell your doctor everything, because it is important. There is no need to beat around the bush. You have to tell the truth, because then, there can be different outcomes." (Study III, male patient, aged 65 years, vocational education).

\subsubsection{Respecting the Doctor's Time}

Patients are aware that the time of the visit is limited and try to not over-run unnecessarily, even if sometimes they feel a need to talk to the doctor about topics other than health-related problems.

"I wish I could talk to the doctor just as I am talking to you now; I have the gift of the gab, a lot of life experience and can talk on any subject, I could talk a lot, but I don't dare, I don't want to waste her [doctor's] time. If I had a serious problem, a dramatic situation, I could share it with a doctor, but I have no need for that, to speak about it. (...) I think that her time is too precious. People waiting in line, and I can find myself a friend to talk to, I have a sister. And here, with the doctor, I do not see the need." (Study II, female patient, aged 68 years, secondary education).

\subsubsection{Creating a Relaxed Atmosphere During the Visit}

Some patients mentioned that, through their behaviour, they felt they could affect the doctor's behaviour and contribute to a relaxed atmosphere during the visit. This applied to both verbal and nonverbal behaviour.

"I think that doctors represent a certain standard; if you act politely, they are polite." (Study II, female patient, aged 68 years, secondary education). 
"She [the doctor] always has a smile on her face. And I've got a smile on my face as well." (Study III, female patient, aged 87 years, secondary education).

Others, however, exhibit a more passive attitude and with their behaviour do not try to interfere with the doctor during the visit.

"I could not talk so much, because the doctor was writing, I did not want to disturb her. (...) That is to say, I did not want to bother her and I had nothing to talk about." (Study I, female patient, aged 79 years, primary education).

Sometimes patients state explicitly that they themselves can contribute to a good relationship with the doctor during the visit.

"It is typical for me that I tell my doctor specifically what I mean, and I get a specific answer, and it's fine." (Study II, female patient, aged 68 years, secondary education).

\subsection{Patient's Contribution to Satisfaction with the Appointment}

Interestingly, the interviews also highlight how patients themselves feel they can influence their own satisfaction with the visit, e.g.:

"I am always satisfied because I will always force the doctor to be polite [laugh]. (...) One needs to talk to the doctor pleasantly, with no fussing; if the patient is polite, the doctor would not feel pressured. The doctor is also human - stressed and tired. The patient can be dissatisfied if the doctor himself feels unwell." (Study III, female patient, aged 79 years, primary education).

"The patient should also be kind to a doctor, because the doctor has taken the time to come and see me and look after me. I am grateful and also satisfied. Hence, there should be care on both sides." (Study III, female patient, aged 81 years, primary education).

Some participants notice their negative impact on family doctor behaviour, and consequently on the whole visit. They also emphasise the significance of cultural background.

"You can see that in the waiting room. In the end, the doctor gets angry, because a patient comes and becomes angry whilst waiting for the visit (...) Yes. Usually patients in the waiting room talk about negative things. And we Poles are particularly prone to this. (...) It affects our mentality. Finally, the patient comes to the doctor's office furious, he doesn't have to say anything but he behaves strangely and that affects the doctor. That's why the entire visit may not go well." (Study II, male patient, aged 75 years, higher education).

"There may be patients who annoy the doctor, because they don't understand anything and they start screaming straight away (...) There are such. It's annoying.
Sometimes people project their family problems at work, and others do the opposite - all right at work but not at home. Also, a lot of people have no time and no job, people are unemployed and it's all just getting worse." (Study II, female patient, aged 51 years, secondary education).

\subsection{Concern for the Doctor, Understanding the Doctor's Situation and Showing Empathy}

Patients showed their concern for the doctor and understanding of the nature of his/her work, even that s/he may be having an "off day":

"Sometimes the doctor can also be unwell and tired. He's not an artist, but a doctor." (Study I, female patient, aged 67 years, secondary education).

"Also, there is nothing to complain about, when you hear how busy these doctors are, working for pennies, I do not like that." (Study II, female patient, aged 51 years, secondary education).

Some patient statements emphasised that the doctor is also a human being with feelings and emotions.

"Perhaps, sometimes the doctor also needs someone to talk to, a smile or a good word, he also needs that, I guess. (...) He is not a stone, but a human, and similarly he has a heart, and wants to be treated like a human being. I think so." (Study III, female patient, aged 70 years, primary education).

Some patients even rationalise doctor's negative behaviour, voicing an appreciation that the doctor is human as well.

"I understand it all, but in the end she [the doctor] should say I'm sorry, I had a bad day today, I'm overworked and upset, please understand me. And that's it! (...) It would be enough! Exactly that would be enough. She is a human, she is not an automaton or a machine, she is a human being and I see no reason for her not to have a right to be tired or upset; there were just a lot of patients that day." (Study II, male patient, aged 57 years, higher education).

"A couple of times when there was no effect, I just tell that to my doctor, but I know that he is also a human being and is not capable of everything, and everyone's body is different, not all patients can be cured with the same drug." (Study II, male patient, aged 75 years, higher education).

Some appeal to their faith and pray for their doctor, for instance: "Sitting in the queue, I pray for the doctor, I ask God for things." (Study III, female patient, aged 70 years, primary education).

Additionally, reciprocity theory in doctor-patient encounters is aptly encapsulated in a statement offered by one of the participants: "I wouldn't like to hurt anyone, and I expect the same from a doctor." (Study I, female patient, aged 64 years, secondary education). 


\section{Discussion}

Interpretation of these diverse experiences of patients using the services of family doctors has allowed us to develop a broader and deeper understanding of the role the patient has in influencing the course and nature of his/her medical appointment. The qualitative data analysed show that the patient's involvement facilitates the visit, and has an impact on satisfaction regarding the visit. In addition, the patient's role implies concern for the doctor and understanding of his/her situation. Patients demonstrate a high degree of empathy by recognising the doctor's emotions. It can be combined with justification of negative experiences of the visit.

The prominence of the patient's subjectivity and activity in the doctor-patient relationship, which was frequently postulated in previous reports [1] and also observed in our own study, demonstrates another relatively new aspect: the patient as a facilitator of the medical appointment. This implies that the patient's role facilitates the visit and allows better cooperation between the two parties. However, a natural consequence of this evident subjectivity and activity of the patient is his/her acceptance of greater responsibility for what the visit is like. Other work has shown that doctors are generally quite open toward active patient behaviour in the visit [14].

The reciprocity theory promulgated by Roberts and Arugute [3] in doctor-patient encounters is supported by the present study. Patients' statements show that, during the visit, they feel obliged "to give back the good that is given to them". This is manifested as patient concordance with medical recommendations, willingness to cooperate with the doctor, creation of a relaxed atmosphere during the visit and the expectation to be treated in the same respectful way that patients treat the doctor. The principle of reciprocity is a cultural pattern requiring reciprocation for benefits and goods received. It takes on a special meaning in the context of medical activities that relate to such goods and values as health and life. It is clear from the statements of patients that they have that norm deeply internalised. It has been reported by Langewitz et al. [15] that the use of typical patient-centred techniques (e.g. professional pauses, the repetition of a word that the patient said or summarising) considerably increases information gathered from patients. These data and our findings highlight a need for patient-centred communication skills.

The present analysis suggests that patients allow the doctor the right to be vulnerable (as a human), and display an understanding of the nature of his/her work. Patients' statements should be considered in their cultural context. Population surveys carried out in European countries (Germany, Italy, Poland, Slovenia, Spain, Sweden,
Switzerland and the UK) demonstrate that respondents from Poland reported low rates of satisfaction with doctors' communication skills and have low expectations of involvement in treatment decisions [16]. Conversely, our previous qualitative analysis revealed that Polish patients have difficulties with expressing negative evaluations of healthcare. The high social status of doctors and low position of patients as evaluators of healthcare are important reasons why patients avoid giving negative evaluations [11]. Although Poland still has a predominately paternalistic model of healthcare and thus relative submission of the patient to the doctor, there is a growing willingness of patients to cooperate with the doctor and to make personal decisions about health. When interpreting the results of the analysis we should consider the context of medical care provided by family doctors, where the relationship between doctor and patient is particular and individual. Hence, we see some patients have a need to share family problems with the doctor. However, as this work features older patients, there may be differences when considering younger patients who were not explored in this study.

A homogenous design and the uniform method of analysis are the major strengths of this study, i.e. all of the in-depth interviews were conducted by the same person (LM), who was not directly involved in providing healthcare services, and was trained in the delivery of qualitative research. The three studies were designed and carried out by a multidisciplinary team consisting of a sociologist, a psychologist, a doctor and a researcher trained in qualitative research. The uniformity of these studies related not only to their subject matter and methodology, which were standardised, but also to the research team; thus, these factors might be viewed as a limitation, but could also be considered as a strength. This paper is a synthesis of qualitative interviews with patients concerning their visits to the doctor; a limitation is that we did not record their interactions with these doctors and therefore cannot in this paper relate our findings to actual observations of the interactions; however, this approach is an area for future research.

\section{Conclusion}

This study concerning patient-doctor interactions shows that each participant (i.e. patient and doctor) can explicitly provide emotional support for the other, despite the evident asymmetry in the roles of doctor and patient. Patients can substantially contribute to the personalisation of their relationship with the doctor, which is often facilitated by the repetition and regularity of the interaction. Patients not only declare their empathy for doctors, but they can also avoid displaying a self-centred attitude, which further 
opens up perspectives for their effective participation in the treatment process.

Author Contributions LM-conception and design, analysis and interpretation of the data, drafting the article; TP-conception and design, analysis and interpretation of the data, revising the article; $\mathrm{JK}$ - analysis and interpretation of the data, critical revision and editing of the manuscript; $\mathrm{SC}$ - analysis and interpretation of the data, revising the article. All authors read and approved the final manuscript. LM acts as the guarantor for the overall content.

Conflicts of interest There were no conflicts of interest affecting any of the four authors.

Acknowledgements This work was supported by the Medical University of Bialystok (Poland). We thank Ryszard Grebowski, sociologist from the Medical University of Bialystok (Poland), for contributions to the data analysis.

Open Access This article is distributed under the terms of the Creative Commons Attribution Noncommercial License which permits any noncommercial use, distribution, and reproduction in any medium, provided the original author(s) and the source are credited.

\section{Appendix}

The interview guide-Study I

- What are your general experiences with the use of family doctor services?

- What are your expectations of the doctor's office visit?

- What was your last visit at the family doctor's like?

- Have your expectations of the visit been fulfilled?

The interview guide-Study II

- What are your experiences with the use of family doctor services?

- What does it mean to you to be satisfied with the visit at the family doctor?

- Is there anything you are especially satisfied with?

- In what circumstances are you dissatisfied?

- Have you experienced any particularly dissatisfying situations?

- What was your last visit at the family doctor's like?

The interview guide-Study III

- In your opinion, what was the most important aspect in the family doctor consultation?

- What does it mean to you to be satisfied with a family doctor consultation?

- What did you like most in the family doctor's behaviour you saw?
- Which of your family doctor's behaviours did you dislike?

\section{References}

1. Coulter A. The autonomous patient: ending paternalism in medical care. London: The Nuffield Trust; 2002.

2. Pendleton D, Schofield T, Tate P, Havelock P. The consultation: an approach to learning and teaching. New York: Oxford University Press; 1984.

3. Roberts CA, Arugute MS. Task and socioemotional behaviors of physicians: a test of reciprocity and social interaction theories in analogue physician-patient encounters. Soc Sci Med. 2000;50(3):309-16.

4. Ong LML, de Haes JCJM, Hoos AM, Lammes FB. Doctorpatient communication: a review of the literature. Soc Sci Med. 1995;40(7):903-16.

5. Ben-Sira Z. Affective and instrumental components in the physician-patient relationship: an additional dimension of interaction theory. J Health Soc Behav. 1980;21:170-80.

6. Hall JA, Roter DL, Katz NR. Meta-analysis of correlates of provider behaviour in medical encounters. Med Care. 1988;26(7):657-75.

7. Adams R, Price K, Tucker G, Nguyen AM, Wilson D. The doctor and the patient: how is a clinical encounter perceived? Patient Educ Couns. 2012;86:127-33.

8. Czachowski S, Piszczek E, Sowińska A, olde Hartman TC. Challenges in the management of patients with medically unexplained symptoms in Poland: a focus group-based study. Fam Pract. 2012;29(2):228-34.

9. Marcinowicz L, Grębowski R. Ocena opieki zdrowotnej z perspektywy pacjenta: zastosowanie analizy jakościowej. [Evaluation of health care from the patient perspective: the use of qualitative analysis]. Fam Med Top 2006;2(15):13-8 (In Polish).

10. Marcinowicz L, Chlabicz S, Grebowski R. Understanding patient satisfaction with family doctor care. J Eval Clin Pract. 2010;16:712-5.

11. Marcinowicz L, Grębowski R, Chlabicz S. Exploring negative evaluations of health care by Polish patients: an attempt at crosscultural comparison. Health Soc Care Commun. 2009;17:187-93.

12. Marcinowicz L, Oleszczyk M, Bielska D, Chlabicz S. Priorities in family physician's care in opinion of elderly people. Fam Med Prim Care Rev. 2012;14:58-62.

13. Strauss A, Corbin J. Basics of qualitative research: techniques and procedures for developing grounded theory, 2nd ed. Thousand Oaks: Sage Publications; 1998.

14. Pawlikowska T, Zhang W, Griffiths F, van Dalen J, van der Vleuten C. Verbal and non-verbal behavior of doctors and patients in primary care consultations: how this relates to patient enablement. Patient Educ Couns. 2012;86:70-6.

15. Langewitz WA, Loeb Y, Nübling M, Hunziker S. From patient talk to physicians notes: comparing the content of medical interviews with medical records in a sample of outpatients in internal medicine. Patient Educ Couns. 2009;76:336-40.

16. Coulter A, Jenkinson C. European patients' views on the responsiveness of health systems and healthcare providers. Eur J Public Health. 2005;15(4):355-60. 